University of Rhode Island

DigitalCommons@URI

Open Access Master's Theses

1999

\title{
A Study of Academic Procrastination in College Students
}

Janee K. McFadden

University of Rhode Island

Follow this and additional works at: https://digitalcommons.uri.edu/theses

\section{Recommended Citation}

McFadden, Janee K., "A Study of Academic Procrastination in College Students" (1999). Open Access

Master's Theses. Paper 1671.

https://digitalcommons.uri.edu/theses/1671

This Thesis is brought to you for free and open access by DigitalCommons@URI. It has been accepted for inclusion in Open Access Master's Theses by an authorized administrator of DigitalCommons@URI. For more information, please contact digitalcommons-group@uri.edu. 


\title{
BF637 \\ $P 76$ \\ $M 334$ \\ 1999
}

\section{A STUDY OF ACADEMIC PROCRASTINATION \\ IN COLLEGE STUDENTS}

BY

JANEE K. MCFADDEN

\begin{abstract}
A THESIS SUBMITTED IN PARTIAL FULFILLMENT OF THE REQUIREMENTS FOR THE DEGREE OF

MASTER OF SCIENCE
\end{abstract}

IN

HUMAN DEVELOPMENT AND FAMILY STUDIES

UNIVERSITY OF RHODE ISLAND

1999

\#45231139 
Abstract

As competition in the work force steadily increases, higher education in the twentieth and twenty-first century is of extreme importance. Academic success entails persistence as well as effective work habits. Despite the undeniable importance of a strong, successful college education, there is one recurring behavior directly related to one's college experience and success that has been consistently overlooked--the behavior termed procrastination. It is estimated that between 75 to 95 percent of all college students engage in academic procrastination. It is this same common behavior that may severely impact one's potential for success in college and subsequently in future endeavors.

This study investigated the prevalence of academic procrastination in college students that experienced academic failures, as well as reasons underlying procrastination behavior. The results were compared to a published assessment of typical students in other college settings.

The sample for this study was obtained from the University of Rhode Islands' Program for Academic Study Skills and Success (PASS). Tests of proportion and correlation matrices were used to compare PASS program 
students to students from a normal academic sample (Solomon \& Rothblum, 1984). Results of this investigation showed that there were similarities between the groups when comparing frequency of procrastination and well as reasons underlying procrastination. This study found that there was not a significant correlation between grade point average and frequency of procrastination due to a restricted GPA range. However PASS program students had a significantly higher level of procrastination in categories of studying and reading when compared with other published results. Recommendations for future research and interventions are offered. 
Acknowledgements

There are a number of special people who have my gratitude for their strength, encouragement and support throughout this past year.

First, I'd like to thank my committee members, Jerry Schaffran, Katie Douglas, John Boulmetis and Richard Sullivan. Your guidance and feedback and support are thoroughly appreciated. I thank Bill Disch for his diligent work on the project as well as for his helpful feedback. I'd like to give a special thanks to my major professor and friend, Jerry Schaffran. It has truly been a pleasure working with you and learning from you. You will be sorely missed.

Finally, I'd like to thank my mother, Dolores McFadden for always believing in me, and for her prayers, I couldn't have asked for a better mother. And last, but certainly not least a special thanks to Tamer Nawar, my pillar of strength for my entire stay in graduate school. You can not know how much I appreciate you. Thank you. 


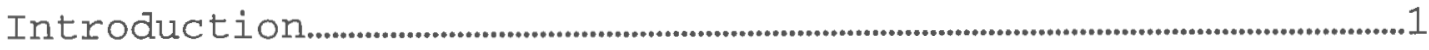

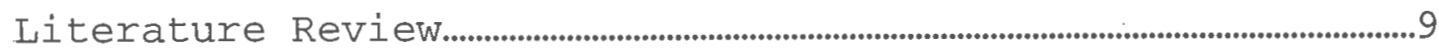

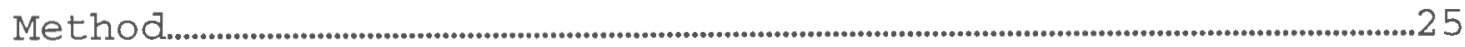

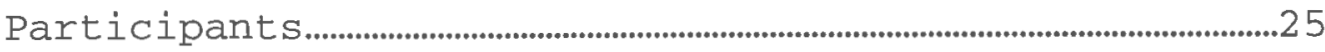

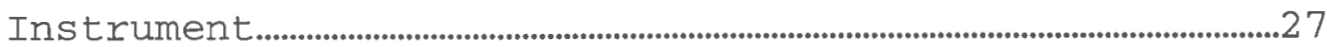

Procedure......................................................................................................................................2

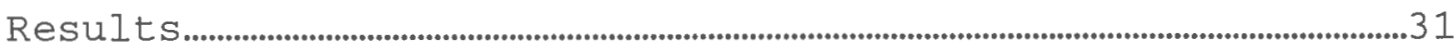

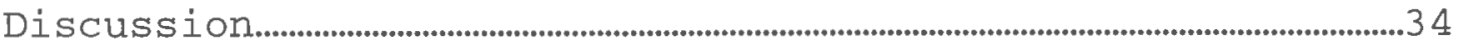

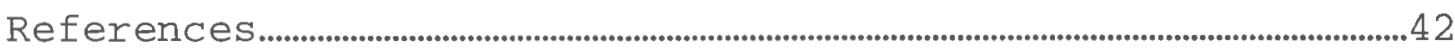

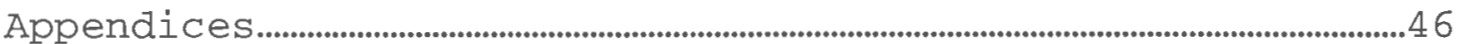

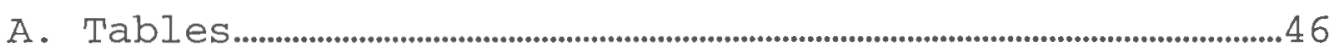

B. Informed Consent.........................................................................................................51

Instrument...................................................................................................................55

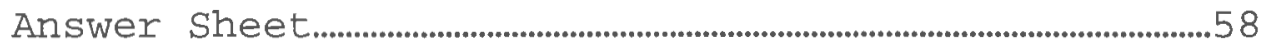

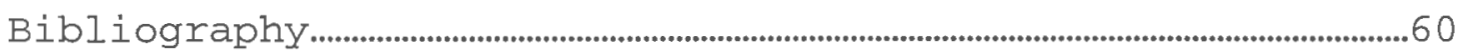


Table 1

Description of sample. .46

Table 2

PASS results means and standard deviations of the procrastination sub-scales, writing, studying, and reading

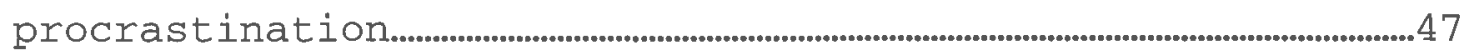

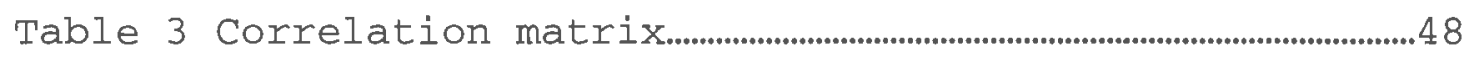

Table 4

Percentage comparison of Solomon \& Rothblum's "high" procrastinators, with PASS program students. 49

Table 5 part 1 Fear of Failure and Task

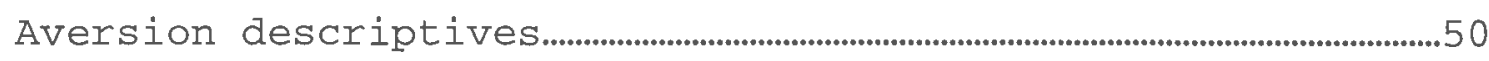

Table 5 part 2 Ranges of scores on reasons underlying procrastination. 
Introduction

The Problem

Procrastination, or task-avoidance, is a behavioral phenomenon that permeates the lives of innumerable people to varying degrees on a daily basis. Despite continuous effort, the ability to avoid procrastination and its undesirable effects often eludes the most competent of individuals. Delaying a task can often lead one into rushing and playing "catch-up" at the last minute. Procrastinators constantly stumble, delay, and panic in response to a demanding responsibility, often facing public scrutiny and judgment.

Competition is pervasive in our culture (Burka \& Yuen, 1983). With competition comes the need for high paced performance, which can be stifled by procrastination. Given the demanding, fast-paced schedules of the twentieth century, the identification, study, and treatment of procrastination is being increasingly undertaken.

The tendency to procrastinate results in an increased level of anxiety and anxiety related problems (Solomon \& Rothblum, 1984; Rothblum, Solomon \& Murakami, 1986; Roberts, 1995). Therefore, increased levels of anxiety could potentially impact one's physical health. For example, factors such as stress and anxiety have long been 
associated with physical ailments such as heart disease, high blood pressure, and ulcers. When rushing to meet imposed deadlines or expectations, the procrastinator may be particularly vulnerable to high levels of stress, and consequently, the physical elements typically associated with stress.

In a highly technological society that places value on expediency and efficiency, procrastination often leads to a "sense of helplessness, feelings of being overwhelmed and a lack of a sense of accomplishment" (Knaus, 1998, p. 8). Ultimately self-esteem may suffer and mental anguish may ensue as a result of engaging in procrastination. Procrastination in a highly industrialized, western society such as the United States is perceived as a malady, something in need of fixing. In a society where ultimate maximization of time is valued, behavior such as procrastination undermines efficiency, and yields the opposite outcome. According to Ferrari (1995), the more industrialized a society, the more salient the construct of procrastination.

In addition to the internal feelings of psychological distress, procrastination has concrete and tangible effects on one's personal, social or professional physical environment. Every April 15 ${ }^{\text {th }}$, thousands of taxpayers 
subject themselves to tax fines because of waiting until the last minute. When procrastinating, important projects crucial to self-development may never get completed, and opportunities may be forever lost because of inaction (Knaus, 1979,1998). Consequences of procrastination may vary depending on the frequency and severity of the habit. Others often penalize procrastinators in the form of fines, late fees, poor treatment and little respect. Because of the negative connotation in this culture, procrastination can frequently lead people into rushing and playing catch up in situations where others must evaluate them. For example, a procrastinator may be negatively evaluated in the workplace by a supervisor for his inability to meet an imposed deadline with a quality finished product.

Given the multitude of deadlines and tasks commonly associated with academic life, students are particularly vulnerable to the tendency to procrastinate and its unfavorable outcomes. Twenty years ago, Ellis \& Knaus (1977) estimated that about $95 \%$ of all college students procrastinated. McCown \& Roberts (1994) assert that procrastination is a demonstrably significant problem for over 25\% of college students. Although there is a clear disparity in percentages reported in previous research, one thing remains clear; procrastination has consistently 
remained prevalent for a significant number of students over a period of twenty years or more.

Student Data

Studies of college students have found that a student's procrastination will increase as he or she advances in class standing (Roberts, 1995). Hill's study of academic procrastination in college students from a variety of college and university settings in the East and Midwest reported the following: $27 \%$ of all students surveyed reported "frequent academically-related procrastination", 25\% reported procrastination approximately half of the time, which when these totals are combined indicate that $50 \%$ of students report procrastinating most of the time (Roberts, 1995). Similarly, forty-six percent of Australian students reported frequent procrastination (Beswick, Rothblum, and Mann, 1988). In a study by McGown \& Johnson (1989), 25\% of adults reported frequent procrastination. According to Knaus, $95 \%$ of college student procrastinate in "notable ways" and $25 \%$ have serious procrastination habits (Knaus, 1979, 1998).

Solomon \& Rothblum (1984) reported that about 25\% of all college students reported problems with procrastination 
on tasks such as writing term papers studying for exams, and keeping up with weekly reading assignments.

Students often have the perception that last minute pressure enables them to produce their best work. However, given the likelihood to miscalculate time needs, a student may often be in a position where they do not have sufficient time to catch errors and fine tune work. Although some students are convinced that last minute work forces them to produce or perform, they will often admit that it is a nerve-racking, highly stressful situation. Despite the highly charged feelings associated with rushing, one may feel stuck in a cycle of waiting until the last minute, rushing, kicking himself or herself, swearing off the behavior for good, and ultimately doing it all over again. Most people would probably agree that they are envious of well-prepared, highly organized peers and would even desire to emulate them. So why procrastinate? Why not just change? What are some of the factors and reasons that people do not and can not stop procrastinating? Definitions

Procrastination has received a deceptively simplistic and ambiguous meaning in its everyday usage. Procrastination is a commonplace term that has come to be utilized to describe a variety of actions or behaviors. The 
term is often used interchangeably with laziness and taskavoidance. A brief analysis of the concept enables us to more seriously consider a behavior that is often casually derided but that can be profoundly debilitating for individuals and economically devastating for schools, businesses, and communities.

Academic and professional psychologists have undertaken the task of defining procrastination. According to a leading forerunner (Silver, 1974) the central defining concept of procrastination is that the individual who procrastinates does not intend to not do the task, they just put the task off past the optimal time it should be initiated to increase the chances of successful completion. Procrastination is not always the same behavior as task avoidance, since under certain circumstances, it makes sense to avoid or postpone a task. The differentiating factor is that, in procrastination, a person has acknowledged the need and desire to complete a task, yet fails to do so.

Modern psychologists and researchers have defined procrastination as "the purposive delay in beginning or completing a task to the point of experiencing subjective discomfort" (Ellis \& Knaus, 1977;Solomon \& Rothblum, 1984; Ferrari, 1992 p. 98). According to psychotherapists Burka 
and Yuen (1983), procrastination is the behavior of postponing. Procrastination only becomes a problem once the delay becomes troublesome to the individual. With both definitions, procrastination is only recognized as significant once it creates a form of discomfort for the individual. In sum, procrastination is occurring only when the procrastinator is both putting off a difficult, important task in favor of something easier, quicker, and less anxiety-provoking, while also delaying vital actions until the performance and results are less than they would have been if done in a timely manner. Key components are the threat to the the identification of discomert-by the procrastinator. While procrastination can clearly encompass all facets of daily life, academic procrastination clearly focuses on this behavior as it pertains to scholastic activities. Beswick, Rothblum \& Mann (1984) defined academic procrastination as the self reported tendency to (a) nearly always or always put off academic tasks and (b) nearly always or always experience problematic levels of anxiety associated with this procrastination.

As noted, the literature indicates that procrastination has far-reaching negative effects on a large number of people. Procrastination can impact a person 
physiologically, mentally, and financially. The present study was undertaken with the hopes of contributing to the understanding of this under-investigated area of college student procrastination. More specifically, the study will focus on a population of college students that would benefit from a better understanding of their personal tendencies and how these tendencies impact their academic and personal lives.

Given the potential for self-harm, impairment or disadvantage, procrastination is hereby defined as dysfunctional academic behavior. Dysfunctional procrastination for the purposes of this study is defined as constant, irrational avoidance of a specific task that needs to be accomplished for the benefit of the individual In other words, failure to accomplish the task is clearly hindrance to success or achievement for the individual.

The following sections will investigate the historical uses of this concept, followed by a review of how the behavior may impact college students. Additionally, the question of why so little help is offered to these students for their procrastination is explored, while also exploring the obvious links between procrastination and other related psychologically based constructs. Other topics to be explored include the various approaches to procrastination, 
procrastination interventions, and relationships among procrastination and other maladaptive behaviors.

\section{Literature Review}

Procrastination has been a human characteristic in societies dating far back into antiquity, with its vestiges evident in historical discourse. In 1742, Edward Young described procrastination as the "thief of time." Marquis later described it as, "the art of keeping up with yesterday" (Ferrari, Johnson, \& McGown, 1995). Despite the historical presence and known destructive qualities, solutions to this common behavioral trait remain an enigma to most. The aforementioned descriptions denote that procrastination has clearly been an unfavorable quality, in essence, robbing human beings of precious time. Although this behavior is commonly referred to, procrastination is most likely one of the least understood of human behaviors. The perception of this behavior is largely dependent upon one's frame of reference, and therefore it is informative to explore multiple perspectives of procrastination.

Procrastination has been a part of the English language for over 400 years with its origins derived from the Latin verb procrastinare. Pro, an adverb implying, "forward motion", and crastinus meaning "belonging to 
tomorrow", equals literally, "forward motion tomorrow", or more commonly, "to put off until another day" (Ferrari, et. al, 1995, p.4). Ironically, citings of this term in Latin texts appeared to positively reflect an often wise decision to exhibit patience in certain situations (Ferrari et. al, 1995). Similarly, the ancient Egyptians possessed two verbs, one of which "denoted the useful habit of avoiding unnecessary work while the other denoted the harmful habit of laziness in completing a task necessary for one's livelihood" (i.e. tilling the soil) (Ferrari et. al, p. 4, 1995). The original meaning of this word was not always negative and, in fact, procrastination often signified a sensible, purposeful delay or postponement of a task. Although the word procrastination has been a part of written language for some time, its meaning has shifted, and continues to evolve with the shift in societal values and behaviors.

Beyond definitions, researchers have attempted to break the construct into categories or classifications. The following types touch on the major ways that this behavior is commonly classified, and demonstrate how it may vary in complexity and frequency.

Dysfunctional procrastination has been defined as starting at a time past the optimal beginning point for 
completion of an important task that has a high probability of needing completion, and that does not have high unreasonable demands or personal costs associated with attempted completion (Ferrari, 1993, Ferrari et al; 1995). Rational or functional procrastination is a similar behavior, evoked for actions that have a low probability of needing completion, or have excessively high costs associated with personal completion at their optimal time (Ferrari, 1993; Ferrari et al 1995). The primary difference between rational and dysfunctional procrastination is that the level or severity of consequence is increased in the latter form. Procrastinatory behavior may also be labeled as either state or trait procrastination (Hong, 1998; Roberts, 1995). When one's behavior is strictly situational (i.e. occasional) it may be characterized as state procrastination. Conversely, when an individual's procrastination has become so pervasive that it can now be considered as a part of his/her personality, it is categorized as trait procrastination, an attribute of personality that maintains a "lifestyle of avoidance" (Roberts, 1995, p. 2). Roberts' state or trait classification system is equivalent to Ferrari's definition of functional versus dysfunctional procrastination. 
Styles \& Types of Procrastination

Procrastination can also be broken down into subcategories, which further identify levels and patterns of this behavior. Decisional procrastination involves forgetfulness and underestimation of time. Decisional procrastination is described as the purposeful delay in making decisions within some specified time frame (Effert \& Ferrari, 1989). Decisional procrastination is performed when one delays thoughts about conflicting alternatives (Janis \& Mann, 1977, Effert \& Ferrari, 1989). Decisional procrastination is a more cognitive type of procrastination, whereas academic and daily procrastination are perceived as behavioral constructs (Effert \& Ferrari, 1989). In a study examining three psychological explanations of procrastination, a small yet significant correlation was found between indecision, irrational beliefs and low self-esteem (Beswick, Rothblum \& Mann, 1988). In Rothblum, Solomon and Murakami's (1986) study of affective, cognitive, and behavioral differences between high and low procrastinators "self-reported procrastination was positively correlated with delay in taking self-paced quizzes, and was negatively correlated with grade point average" (p. 387). 
Low-grade procrastination is another categorization used to describe when one does not take care of things and handle the smaller tasks and chores, that when added up or combined over time, may or may not have significant effect. Knaus $(1979,1998)$ describes this occurrence as "a lot of little things that add up to a real inconvenience" (p. 30). Psychologists suspect that low-grade procrastination is likely the most difficult type of procrastination to overcome.

Maintenance procrastination involves putting off the type of activities that support the efficient running of one's daily life (Knaus, 1998). Maintenance procrastination includes delaying self-maintenance tasks such as paying bills, keeping appointments, checking, household chores, etc. Clearly this form of procrastination may appear minimal on the surface, but can have significant effects on interpersonal relationships, and professional life.

Developmental procrastination is characterized by the avoidance of activities that would promote personal growth (Knaus, 1998). For instance, delaying the relinquishment of bad habits, such as smoking or overeating, avoiding tasks that would ultimately improve career development, and 
the avoidance of spiritual and educational interests, all fall under this category (Knaus 1998).

Hindrance is another type in Knaus' procrastination typology. In this form, one's behavior is characterized by consistent acts of self-indulgence that have long term unpleasant personal consequences (Knaus, 1998). In hindrance procrastination, the perpetrator considers doing whatever is pleasurable to him/her even if this substantially impacts the lives of others. Hindrance may be manifest in four ways: hostility, rebellion, indifference, and lateness (Knaus, 1998).

\section{Reasons for Procrastination}

There are multifaceted conceptualizations, which attempt to outline the reasons people procrastinate. Although procrastination is a complex construct comprised of thinking, feeling and behavioral components, this behavior is simply attributed to poor time management and laziness (Roberts, 1995). Procrastination research, both old and new, explores some of the major underlying causes of procrastination. Although procrastination is a common occurrence for most people to some degree, it can become a major influence on lifestyle when considering people who maintain life habits with which they are clearly dissatisfied. Motivations underlying procrastination are 
related to diverse personality traits, and result in a range of patterns of avoidance (Roberts, 1995).

Among these personality variables, perfectionism is frequently explored (Ellis \& Knaus 1977; Knaus, 1979, 1998; Burka \& Yuen, 1983; Roberts 1995; Sapadin, 1996). When an individual has set unrealistic and unattainable standards for her or himself, frustration and a sense of dissatisfaction are certain to follow. According to Ellis and Knaus (1977)--pioneers in procrastination research-emphasis on meeting goals perfectly increases the likelihood of disappointment and ultimately withdrawal. Perfectionism also includes over-extending oneself and attempting to satisfy everyone well beyond one's means. In essence, spreading oneself too thin is often correlated with procrastination. According to Sapadin (1996), perfectionism is different from having high standards of achievement. Perfectionists create unrealistically high goals for themselves, which in turn paralyze the perfectionists from moving to achieve these goals. A comment lament might be, "it's all or nothing," or "I want it done right." Perfectionism can also be related to procrastination in another way. Procrastinators can also provide a situation where circumstances are beyond their control (Sapadin, 1996), thus presenting an excuse for poor 
outcomes and/or mediocre performance. Sapadin (1996)

characterized the perfectionist logic as follows; "...if they choose not to take a particular challenge seriously, either by not doing anything at all about it, or by treating it in a very offhand, casual manner, they can spare themselves the tyrannical, self-imposed responsibility of being perfect" (p.38). Knaus (1979, 1998) defines perfectionism as, "a dire need to be thoroughly competent, intelligent and achieving in all possible aspects according to the perfectionist" (p. 99) According to Knaus $(1979,1998)$ perfectionism can be correlated with contingency theory since one's own self-worth is often contingent upon achievement of perfectionist standards.

A close relative of perfectionism, fear of failure, is another construct often associated with procrastination. Fear of failure encompasses significant apprehension about being judged and being found lacking or not good enough (Burka \& Yuen, 1983). Procrastination is a coping strategy for fear of failure because it allows one to delay the answer to an inevitable question--Can I actually live up to the aspirations and dreams that I've established for myself? (Burka \& Yuen, 1983). Sapadin (1996) categorizes this sort of behavior as the worrier procrastinator. Individuals who worry too much are more apt to remain in 
their own comfort zone because it involves less threat and potential for harm or damage. Research on academic procrastination has been positively correlated to selfreported fear of failure and task aversiveness (Beswick, Rothblum, Mann 1988; Effert \& Ferrari, 1989). Solomon \& Rothblum (1984) found fear of failure to account for $49 \%$ of the variance in a factor analysis of reasons why students procrastinate. They also reported that task aversiveness accounted for another $18 \%$ of the variance of academic procrastination. One study showed that students avoided tasks that they felt they could not complete successfully (Roberts, 1995)

Early research by Ellis \& Knaus (1977) described one motivation underlying procrastination as low-frustration tolerance, a similar concept that sapadin later (1996) coined as dreamer procrastinator. The dreamer procrastinator seeks pleasure by dodging discomfort and being passive in relationship to hard-to-reach goals. Relevant Theories

"People who procrastinate are complex individuals with varied motivations for the postponement of tasks" (Roberts, 1995 p. 13). Procrastination may be viewed from a multitude of social, political, psychological and medical perspectives. Considering procrastination from theoretical 
notions of human physiological development allows for a different approach. Scientists have often characterized human beings as possessing a fight or flight response, which is crucial to one's survival instinct. This biologically structured characteristic prompts one to either fight or flee an opponent when faced with an immediate challenge (Roberts, 1995). When the fight or flight response is activated, one undergoes numerous biological changes, which in turn creates a significant amount of stress. If this response pattern is applied to the process of procrastination, the challenge is perceived to be the task of which one remains fearful. One may either undergo the stress and potential loss/failure associated with the task or challenge, or flee.

Abraham Maslow was a pioneer in exploring motivation theory. Maslow asserted that people are driven by internal motivation, by desires they have yet to fulfill (Maslow, 1999). Motivation is described as the forces acting, or within us that initiate behavior and give it direction (Maslow, 1999). Motivation theory therefore, might offer explanations of procrastination when we consider the need for acceptance, love and fulfillment within Maslow's hierarchy. Because procrastination may be an attempt to preserve one's ego, stave off failure, or conceal 
inadequacy, this behavior may be initiated to maintain feelings of love and higher levels of satisfaction. In other words, inaction or avoidance may be initiated to prevent the possibility of disappointing oneself, thereby maintaining feelings of self-love. Similarly, this behavior may be used to prevent the procrastinator from disappointing others who may have expectations of the procrastinator, thereby maintaining feelings of love from others.

"Psychodynamic" theorists tend to examine procrastinatory behavior from its relationship to childhood experiences (Van de Kolk, 1987; Ferrari, et. al, 1995). Knaus (1979, 1998) partially attributes potential procrastination to children's emulation of poor role models. Childhood conditions may contribute to patterns of adult procrastination in a number of ways. Children who replicate inefficient patterns of behavior from familial or communal units may learn to embrace behavior we call procrastination. Freudian theory would postulate that tasks that are not completed are avoided because they are threatening to the ego (Ferrari et al, 1995). However, difficulty lies in the inability to empirically test some of the psychoanalytic theories. 
"Self-efficacy" theory also lends itself to procrastination research. According to Albert Bandura (1977), one's self-efficacy guides the ability to regulate control over one's life and may ultimately be used as a predictor for certain behaviors (Bandura, 1977; Lent, Brown \& Larkin, 1984). People who embrace the belief that they can exert control over the course of their own lives will "normally coordinate and regulate activities around this belief" (Knaus, 1979, 1998, p. 42). Conversely, those who do not subscribe to the belief that they are capable and efficient will subsequently manifest their own preconceived expectations of failure. In other words, low self-efficacy establishes a belief in inevitable low achievement or lack of control on achievement, which in turn becomes the proverbial "self-fulfilling prophecy." Self-efficacy has several implications for understanding procrastination. The emotions of self-doubt, worry, fear, apprehension may present an almost cyclical effect on procrastinatory behavior. When an individual has low self-efficacy, self-doubt, worry, fear and low selfconfidence are certain to ensue. Although not a selfefficacy study, Beswick, Rothblum, and Mann (1988) found three similar psychological explanations for procrastination in college students: i.e. Indecisiveness, 
low self-esteem, and irrational beliefs about self-worth. If an individual is not confident in his/her ability to perform or accomplish a task, hesitation towards or avoidance of the task is highly probable. Hackett and Betz (1981) asserted that one's self-efficacy is related to one's level of persistence as well as one's overall success in a college major. Bandura's theoretical framework of self-efficacy suggests one's self-efficacy will determine performance and level of persistence (Lent et al, 1984).

Attribution theory (Weiner, 1985) describes concepts similar to self-efficacy theory, and also broadens our understanding of procrastination. Based on this theory, those individuals who attribute their success to individual capability, and their failure to lack of effort, will ultimately persist despite some failures. Conversely, those individuals who attribute their success to circumstances and their failures to innate inability, are more likely to give up when challenged.

Finally, Janis and Mann's (1977)-conflict theory of decision making frames procrastination as a coping mechanism when handling difficult decisions. Procrastination becomes a means for coping with conflict and indecision by providing an escape from making a decision that is causing stress. This theory provides 
insight into the classification of procrastination labeled Decisional procrastination.

\section{Assessing Procrastination}

There are a number of instruments available that are appropriate for the measurement of procrastination in college-age students. Ferrari et al (1995) compiled an exhaustive report of self-report measures of procrastination dating from 1980. His extensive searches revealed seven procrastination measurements with at least two citations. Out of these seven instruments, four of them focus on academic procrastination. For the purposes of this study, which specifically focuses on academic procrastination, only four of the instruments found were relevant. The four instruments are reviewed below. The items discussed were chosen either because of their relevancy to college-age students or because of the frequency of use within existing procrastination research (Ferrari, 1992, Ferrari et al, 1995).

Lay's General Behavioral Procrastination Scale, (GP) is described as one of the "first major measure(s) of selfreported procrastinatory behavior" (Ferrari et al, 1995) (Ferrari, 1992). It is a 20-item instrument which was determined to have good construct validity (Ferrari, 1992). Several studies indicated a Cronbach alpha of .78 was 
determined for reliability (Lay, 1986). Because this instrument largely focuses on a variety of non-academic tasks, it was not selected for this study.

The Tuckman Procrastination Scale seeks to assess procrastination as it pertains to academic behavior (Ferrari, et al 1995). Very few studies have been conducted to test validity of the TPS. According to Ferrari, et al (1995), "the TPS also suffers from insufficient validity assessment with behavioral indices of procrastination" (p. 56).

The Aitken Procrastination Inventory (API) (1982), created as a part of her doctoral dissertation, (Ferrari et al, 1995), was not selected because of the length of time that would be required to complete the 52 -item instrument. The most frequently used self-report measure of procrastination for college students to date is Solomon and Rothblum's Procrastination Assessment Scale for Students (PASS), which explores procrastination of academically related tasks. This instrument seeks to assess the prevalence of and the reasons behind procrastination. In Solomon and Rothblum's original instrument, PASS was designed to assess the frequency of and reasons for procrastination in six academic areas, as well as the 
desire for change. It is composed of 38 items and is divided into two parts.

Part II of the original version of PASS presents the participant with scenarios of procrastination and then asks for a rating on a 5-point scale of 13 reasons for the behavior on a particular task. One benefit of PASS is that it can be used a tool to compare self-reported procrastination with other potentially related constructs such as, fear of failure, task-aversion and perfectionism. Solomon and Rothblum (1984) developed the PASS expressly for college students. It is found to have good reliability and validity as a tool for situation-specific procrastination (Ferrari, 1992). The correlation for procrastination as a problem was .26 overall and for reasons for procrastination was .80 . The stability of the PASS was fair with one-month test-retest correlations of .74 for prevalence and .56 for reasons for procrastination. For the total score, the test-retest correlation was .80 . Solomon and Rothblum (1984) noted that self-report measures of assessing academic procrastination have been criticized for their lack of reliability. For this reason, the Procrastination Assessment Scale for Students has been validated against actual physical delay in taking selfpaced quizzes (Solomon \& Rothblum, 1984), delay in 
submitting course assignments (Rothblum, Beswick \& Mann, 1984), delay in participation in psychology experiments (Solomon \& Rothblum, 1984), and lower course grades (Rothblum, Beswick \& Mann, 1984; Rothblum, Solomon \& Murakami, 1986). Because of its content relevance to this study and its use with college students, the PASS instrument was selected for use in the current study.

\section{Methods}

\section{Participants}

Participants in this study were obtained from the Program for Academic Skills and Success (PASS) at the University of Rhode Island. The PASS program was developed out of URI's University College, the university college that provides numerous services and support to a variety of URI students in their first two years of undergraduate study. The program was created to provide an alternative to students who would otherwise be dismissed academically from the university for low grades. Students who achieve a grade point average of 1.00 or lower in their first semester at URI, are allowed to return to the university in the spring semester under the condition that they participate in PASS. Students who achieve a GPA of a 2.0 or better for the semester, in which they conjointly 
participate in PASS, are allowed to return to the university on a conditional status for the following semester. Students who do not achieve a 2.0 or better while participating in PASS are dismissed from URI for a minimum of one semester and are then required to re-apply for admission if they desire to return the following year. Going on its fifth year, the program was first introduced in the spring of 1994. The goals of the PASS program are as follows:

1. To assist students in identifying the reasons for their lack of academic progress; 2. To aid students in developing responsibility for their academic future

3. To provide encouragement and support in structured group and individual meetings

4. To provide structured time to study 5. To evaluate PASS effectiveness.

After final grades for the fall semester of 1998 were received, each first semester student who received failing grades received a letter from the Dean of the University College explaining PASS and the necessary conditions of the program. Initially, there were 101 students who qualified for academic dismissal at the end of the fall semester of 1998 for failure to meet academic standards. Of those 
students, 77 elected to participate in PASS for the spring semester of 1999 and subsequently had their dismissal waived. Of the 77 who chose to participate, 58 were present at the introductory/orientation PASS meeting held on January 19, 1999. The other 19 students who did not show up for the PASS orientation meeting were automatically dismissed from the university for failure to attend.

The vast majority of the students who participated in PASS for the 1999 Spring semester were $2^{\text {nd }}$ semester freshmen, however there were a few exceptions. There were four transfer students who participated in the PASS program because they received failing grades during their first semester at the University of Rhode Island. Instrument

As noted earlier, the most frequently used self-report measure of procrastination for college students to date is Solomon and Rothblum's Procrastination Assessment Scale for Students (PASS). The revised version of the PASS instrument was shortened in both part I and II by solomon and Rothblum. There is no difference between the shortened version and the original version when interpreting the results, as the scoring ranges are merely reduced in the shorter version (Personal communication, E. Rothblum, November, 17, 1998). The instrument is broken down into 
three sub-categories to measure three types of procrastination-reading, writing, and studying. In each sub-category, the first question assesses the frequency of procrastination, the second question assesses the extent to which procrastination is a problem, and the third question assess the extent to which the respondent would like to change their behavior. The score for the PASS instrument is obtained by adding the scores of the first two questions in each of the sub-categories, i.e., questions \#1 and \#2 from reading procrastination, questions \#1 and \#2 from writing procrastination, and questions \#1 and \#2 from studying procrastination. The lowest score that may be achieved under each category is two, and the highest score achievable is ten. A lower score is indicative of low or infrequent procrastination behavior, whereas a high score represents a high or frequent procrastinator.

Data Collection Process

Binders containing various orientation materials were distributed to PASS students during an orientation period on January 19. Surveys to be included for this study were also included in these binders. Prior to survey completion the Dean of the University College provided an explanation of and directions for the survey. Students were instructed to take ten to fifteen minutes to complete 
the Procrastination Assessment Scale for Students (PASS).

Students were advised to answer each question carefully and thoughtfully. Students were instructed to complete the questionnaire that focused on their specific study habits. They were informed that the survey would help them to start thinking about their behavior when performing certain academic tasks. Students then completed surveys located in the binders and returned them to the PASS counselors. A total of 58 surveys were collected, which represents the entire available population of PASS program students. The six counselors working for the 1999 PASS program assisted with the collection of consent forms during a oneweek time frame (see Appendix B). PASS counselors were required to meet with each of their assigned students at least once a week. During these meetings, PASS counselors requested that students sign consent forms, while also answering any questions about the surveys. In order to request consent from students who did not meet during this week with their PASS counselors, PASS counselors also distributed and collected consent forms during study hall hours during the week. Consent form collection was conducted from March $5^{\text {th }}$ through March $12^{\text {th }}$ for the fiftyeight surveys. Permission to access student's records from University College was obtained through signed consent 
forms. Consent for the researcher to go into student files to collect demographic data and SAT scores were obtained from the Dean of University College and from the office of the provost.

Hypotheses and Analyses

The data collected were entered into SPSS and tested the following null hypotheses:

(1) There is no significant correlation between academic performance (GPA) and self-reported procrastination, (2) The incidence (\%) of high procrastination in the sample will not significantly differ from citations in the PASS literature, (3) No differences in motivational foundations underlying procrastination will be found when compared to published data (Solomon \& Rothblum, 1984).

Null hypothesis \# 1 was assessed using a cross sectional design to test the correlation between academic performance (GPA) and self-reported procrastination. Null hypothesis \# 2 was assessed by comparing percentages of high procrastination with Rothblum's data by using a test of proportion. Null hypothesis \# 3 was assessed by comparing the most frequent reports of underlying motivations for procrastination, as reported by the PASS program students, to Solomon and Rothblum's highest reports 
of underlying motivations. All tests of significance were set at the .05 level.

\section{Results}

Table 1 (Appendix A) provides a description of demographic data of the sample, such as average age of participants, percentage of male and female participants, means for participants' grade point averages (GPA) and means for the Scholastic Aptitude Test (SAT) scores (Verbal, Math, and total SAT scores).

Of the original 58 subjects, data from one subject were not used because of the unavailability of SAT scores for this subject. Additionally, this subject was nonrepresentative of this sample of students, given that he was 36 years of age. The exclusion of this subject brought the number of participants to fifty-seven. The sample for this study was an extremely homogenous group of traditional-aged college students. Approximately 65 percent of the sample was male $n=37$. By far, the majority of participants were Rhode Island residents (40\%), with Connecticut representing the second largest state of residence (12\%). A typical student in this study was 19.65 years old, from Rhode Island, whose major was engineering or business, had combined total SAT scores of 1024, verbal 
SAT scores of 511, math SAT scores of 512, and who finished the fall semester with a GPA of .65 .

Table 2 (see Appendix A) presents the means and standard deviations of the procrastination sub-tests, writing, studying and reading procrastination. The table describes the average scores of participants in each area of procrastination, as well as the means for two major reasons underlying procrastination, Task-aversion (AVERPROC), and Fear of Failure (FEARPROC). Finally the table provides the means for procrastination overall (PROCOVER), which is the total score obtained on the part one of the PASS instrument. The lowest possible score obtainable was six, while the maximum possible score obtainable was thirty.

Table 3 (Appendix A) presents inter-correlations for all variables obtained in this study, such as gender, age, verbal Scholastic Aptitude Test. scores (VERBAL SAT), Math Scholastic Aptitude Test scores (MATH SAT), first semester grade point averages (GPA), sub-tests of the PASS instrument, Writing Procrastination (WRITPROC), studying Procrastination (STUDPROC), Reading Procrastination (READPROC), reasons for procrastination--Fear of Failure (FEARPROC), and Task Aversion (AVERPROC), and the overall procrastination scores (PROCOVER). 
In order to test hypothesis \#I, a Pearson ProductMoment correlation was performed on the relationship between GPA and composite measures of writing, studying and reading types of procrastination. Results indicated that there was no significant relationship between GPA and the three measures of procrastination. (See Table 2 for summary information related to the PASS variables and Table 3 for the correlations). Pearson-Product moment correlations were also performed on all variables such as gender, i.e. age, Verbal SAT, Math SAT, SAT combined, GPA, and multiple subscales of procrastination (See Table 3, Appendix A) . Although nothing was significantly related to gender, age or GPA, the following significant correlations were noted: Total SAT scores were significantly related to writing procrastination, task aversion procrastination, and procrastination overall.

Procrastination overall (PROCOVER) was most highly correlated with writing procrastination, followed by studying procrastination and reading procrastination. It was also significantly related to task aversion procrastination but not fear of failure procrastination.

In order to test hypothesis \#2 that frequency/level of procrastination of PASS program students would be similar to published data, results were compared to solomon \& 
Rothblum's pre-existing percentages using a test of proportion analyses. Results of these tests of probability are listed in Table 4 (see Appendix A). Results revealed that the procrastination related sub-scales of studying were significantly higher than solomon and Rothblum's data (1984). The second category of reading procrastination was also significantly higher.

Because of the way the data are reported in the literature with which this study is compared, the data presented for hypothesis \#3 are of a more descriptive nature. Solomon and Rothblum (1984) reported ranges within percentages for their results of reasons underlying procrastination behavior. A descriptive generalization revealed that there were similarities between the PASS program students' results and the results of solomon and Rothblum's (1984) previous study (See Table 4).

Discussion and Recommendations

This study set out to assess procrastination in college students at the University of Rhode Island. More specifically, the academic procrastination behavior of specific students was explored. For hypothesis \#1, it is not surprising that no correlation between GPA and procrastination was found. As mentioned in previous 
sections, there is conflicting literature on the relationship between GPA and academic performance. Additionally, the range of GPA for this sample was severely limited, given the nature of the PASS program. The compressed GPA range served as an influence on results.

Hypothesis \# 2 sought to compare the frequency of procrastination of typical students at large, with results of URI PASS program students. Although there was no statistically significant correlation in the first hypothesis, a test of the second hypothesis found significantly high levels of procrastination in three subtests for the second hypothesis-when compared to published results. These sub-tests were the two sub-categories of studying procrastination, and one category labeled reading procrastination. A plausible explanation for high scores of studying procrastination may be related to the students' age and transition from high school to college. The homogeneity of the PASS program students makes it apparent that the majority of the students have very recently had their first academic experience in college. The transition of study skills necessary to be successful in college may not yet be incorporated into this group's lives. Additionally, hypothesis \#3 sought to compare PASS program students' reasons underlying procrastination to the 
reasons most frequently indicated in Solomon and Rothblum's (1984) study. As previously mentioned, this comparison is more descriptive in nature, given that the scores were reported as ranges in Solomon and Rothblum's study. Solomon and Rothblum (1984) found that the items endorsed most frequently were fear of failure and task aversiveness, therefore these items were used for comparison with PASS program student's responses. The ranges of scores reported by PASS programs students were strikingly similar to the ranges presented in Solomon \& Rothblum's (1984) study. Both categories are most dominant out of all other potentially reported reasons, yet task aversiveness received the highest endorsement in both the PASS program group and Solomon and Rothblum's group. Task aversiveness appears to be more easily identified by students as a tangible reason for task delay. The PASS program students would be considered typical of solomon and Rothblum's study when considering the ranges reported on task aversiveness and fear of failure.

\section{Limitations}

Because this study is considered post-hoc, it is unwise to make inferences about how procrastination is related to the PASS program students who failed their classes the first semester. Homogeneity of this specialized 
group possibly limits the generalizability of this study. It was purposeful and necessary to focus only on the fiftyeight students that comprised the 1999 PASS program, however such a small sample was a possible limitation. Although this entire population of students within the PASS program was captured, the traits and qualities of these students may not be generalizable to average students at large. The sample consisted of a high percentage of Business and Engineering students (32 percent), and this may have potentially impacted or skewed the results. Similarly, the grade point average data presented an extremely limited range for this study, although it is the GPA range that served as a requirement to student participation in the PASS program. It is interesting to note that although the sample was relatively small, many findings were very similar to the findings of Solomon \& Rothblum's larger study (1984).

$\underline{\text { Recommendations }}$

Recommendations concerning methodology

The current study attempted to assess procrastination with a sample of students who had already experienced academic failures in the semester preceding survey distribution. In order to further investigate the 
relationship betwe procrastination and academic performance, it wor ${ }^{-}-\mathrm{b}$ better to test freshman at the beginning of the semester, prior to the attainment of any grades. This desigr rouid allow researchers to predict the relationship betwee- $\exists$ P? and procrastination rather than just correlate the =ur.

With regards == =yzothesis \#3--reasons for procrastination--spez=-ic percentages need to be found in order to compare resi-ts rather than comparing reported ranges.

Recommendations for E=ture studies

In regards to Mothesis \#1, which tested the relationship betwee= झcedemic performance and GPA, there was no significant $=$ relation between course grades and self-reported proc: $=$ =ilation, which was consistent with Solomon and Rothbl: $\equiv$ Eindings (1984). However, Semb and Glick (1979) had cc= acicting results, as did solomon and Rothblum (1988) in Dtier study. These studies found that students who repor $=\equiv$ Izequent procrastination tended to do less well academics 1 . Future studies should further investigate this ve: irportant area. Future approaches can take a number $=\equiv \equiv 0 \mathrm{~ms}$ : 
1. Administering the PASS instrument to the entire freshman class. In particular for the University of Rhode Island, this instrument may be distributed in URI 101, a mandatory freshman orientation class. This procedure would allow for tracking of student's GPA and overall development as they matriculate into the university. Additionally, students who ended up in the PASS program could re-take the instrument in order to reassess their scores as compared with the overall freshman class.

2. Using the PASS instrument as a diagnostic and intervention tool, which assessed the frequency of and reasons for procrastination, on an itemto-item basis would be useful. In this way, student's who engaged in a particular type of procrastination (i.e. reading vs. writing), and who had a distinctly strong reason for procrastination (i.e. perfectionism, could be distinguished and handled on an individual basis. Recommendations concerning writing and reading subcategories of procrastination

1. PASS program students were found to have higher incidences of writing and studying 
procrastination. It would be beneficial to University college, the college that advises this group of students, to initiate intervention strategies. Using this information, these intervention strategies could include an increase of study skills workshops, as well as courses and workshops that focus on boosting reading skill and retention of information.

2. The sub-categories of writing procrastination and studying procrastination were highly correlated to task aversion. A plausible explanation is that these students who are fairly new to the college environment are not accustomed to studying and writing at the level necessary for college success. This high correlation might also be related to this particular sample which was overrepresented by business and engineering students. In order to remediate task aversion, intervention could include assessment of student skill level for studying and writing, and transition from high school to college based coursework.

Theory based recommendations

Although there are many useful theories that lend themselves to understanding procrastination, there is no 
comprehensive theory that links the numerous categories, levels, and definitions of procrastination. It would be of great use to chart and link the varying conceptualizations of procrastination, while also providing a model for selfchange.

One branch of procrastination theory suggests that procrastination is a learned behavior, possibly emulated from family members beginning in childhood. Studies that seek to examine the prevalence of procrastination in one's family (immediate) and or circle of friends, while comparing this to the frequency of procrastination in the participants would be useful.

Finally, another possible model to explore is selfchange theory (Prochaska, Norcross, \& DiClemente, 1994). It is apparent that some procrastinators change their behavior and self-change theory might help chart the stages of change and the processes of change. 


\section{References}

Bandura, A. (1977). Self-efficacy: Toward a unifying theory of behavioral change. Psychological Review, 84, $191-215$

Beswick, G., Rothblum, E. D., \& Mann, L. (1988). The psychological antecedents of student procrastination. Australian Psychologist, 23 (2), 207-217.

Burka, J. B., \& Yuen, L. M. (1983). Procrastination, why you do it, what to do about it. Reading, MA: Perseus Books .

Effert, B. R., \& Ferrari, J. R. (1989). Decisional procrastination: Examining personality correlates. Journal of Social Behavior \& Personality, 4, 151-156.

Ellis, A., \& Knaus, W. J. (1977). Overcoming procrastination. New York, NY: Penguin Books.

Ferrari, J. (1992). Psychometric validation of two procrastination inventories for adults: Arousal and avoidance measures. Journal of Psychopathology and Behavioral Assessment, 14 (2), 97-109.

Ferrari, J., Johnson, J., McGown, W. (1995). $\underline{\text { Procrastination and task avoidance: Theory, research, \& }}$ treatment. New York, NY: Plenum Press.

Janis, I. L., \& Mann, L. (1977). Decision-making: A 
psychological analysis of conflict, choice, and

Commitment. New York: Free Press.

Hong, E. (1998). Differential stability of state and trait self-regulation in academic performance. Journal of Educational Research, 91 (3), 148-157.

Knaus, W. (1979). Do it now: How to stop

procrastinating. New York, NY: Prentice-Hall.

Knaus, W. (1998). Do it now: How to stop

procrastinating. (Revised edition). New York, NY: John Wiley \& Sons.

Lay, C. H. (1986). At last, my research article on procrastination. Journal of Research in personality, 20, 474-495.

Lent, R., Brown, S., \& Larkin K. (1984). Relation of self-efficacy expectations to academic achievement and persistence. Journal of Counseling Psychology, 31 (3) $356-$ 362 .

Maslow, A. (1999). Toward a psychology of being. $3^{\text {xd }}$ edition. New York, NY: John Wiley \& Sons.

McGown, W. G., \& Johnson, J.L. (1989). Non student validation of an adult inventory of procrastination. Paper presented at the American Psychological Association, New Orleans, LA. 
McCown, W., \& Roberts, R. (1994). A study of academic and work related dysfunctioning relevant to the college version of an indirect measure of impulsive behavior. Integra Technical Paper, 94-28, Radnor, PA: Integra, Inc. Prochaska, J., O., Norcross, J., C., \& DiClemente, C., C. (1994). Changing for good. New York, NY: W. Morrow Publishers.

Roberts, M.S. (1995). Living without procrastination: How to stop postponing your life. Oakland, CA: New Harbinger Publications.

Rothblum, E. D., Solomon I.J., \& Murakami, J. (1986). Affective, cognitive, and behavioral differences between high and low procrastinators. Journal of Counseling Psychology, 33 (4), 387-394.

Sapadin, L., \& Maguire, J. (1996). It's about time: the six styles of procrastination and how to overcome them. New York, NY: Penguin Books.

Semb, G., \& Glick, M. (1979). Student withdrawals and delayed work patterns in self-paced psychology courses. Teaching of Psychology, 6, 23-25.

Silver, M. (1974). Procrastination. Centerpoint, 1, $49-54$

Solomon, I.J., \& Rothblum, E.D. (1984). Academic procrastination: Frequency and cognitive-behavioral 
correlates. Journal of Counseling Psychology, 31 (4), 503509.

Van de Kolk. (1987). Psychological trauma--

Washington DC: American Psychiatric Association Press.

Weiner, B. (1986). An attributional theory of

motivation and emotion. New York, NY: Springer-Verlag. 
Appendix A

Table 1 Description of Sample $N=57$

\begin{tabular}{|c|ccc|}
\hline & Mean & Standard Deviation & Range \\
\hline Age & 19.37 & 0.96 & $19-25$ \\
Gender & $M=37 / F=21$ & - & $00-1.22$ \\
GPA & 0.65 & 0.3223 & 1.22 \\
SAT V & 511 & 67.06 & $380-670$ \\
SAT M & 512 & 72.11 & $380-800$ \\
SAT & 1024 & 118.62 & $850-1470$ \\
\hline
\end{tabular}


Table 2 pass Results

Means and standard deviations of the procrastination subscales, writing, studying, and reading procrastination

\begin{tabular}{|l|cc|}
\hline & Mean & Standard Deviation \\
\hline WRITPROC & 6.5263 & 1.95 \\
STUDPROC & 6.8246 & 1.81 \\
READPROC & 6.6842 & 1.69 \\
FEARPROC & 9.4386 & 3.72 \\
AVERPROC & 14.2807 & 4.90 \\
PROCOVER & 20.0351 & 4.32 \\
\hline
\end{tabular}


Table 3 Inter-correlation matrix of variables

$$
\mathbf{N}=\mathbf{5 7}
$$

\begin{tabular}{|c|r|r|r|r|r|r|}
\hline & GENDER & \multicolumn{1}{|c|}{ AGE } & VERBAL SAT & MATH SAT & \multicolumn{1}{c|}{ SATOVER } & \multicolumn{1}{c|}{ GPA } \\
\hline GENDER & 1.000 & .205 & .163 & .049 & .122 & -.168 \\
AGE & .205 & 1.000 & -.068 & -.084 & -.089 & -.027 \\
VERBAL SAT & .163 & -.068 & 1.000 & $.452 * *$ & $.840 * *$ & -.138 \\
MATH SAT & .049 & -.084 & $.452^{* *}$ & 1.000 & $.864 * *$ & -.172 \\
SATOVER & .122 & -.089 & $.840 *$ & $864 * *$ & 1.000 & -.183 \\
GPA & -.168 & -.027 & -.138 & -.172 & -.183 & 1.000 \\
WRITPROC & -.085 & .029 & $.296 *$ & $.288^{*}$ & $.343 * *$ & .088 \\
STUDPROC & -.092 & -.021 & .179 & .231 & .242 & .064 \\
READPROC & -.029 & .158 & .014 & .101 & .070 & .043 \\
FEARPROC & -.202 & -.148 & -.178 & -.168 & -.203 & .027 \\
AVERPROC & .058 & -.015 & $.329 *$ & $.281 *$ & $.356 * *$ & .036 \\
PROCOVER & -.088 & .066 & .214 & $.266 *$ & $0.283 *$ & .083 \\
\hline \hline
\end{tabular}

\begin{tabular}{|c|r|r|r|r|r|r|}
\hline & WRITPROC & STUDPROC & READPROC & FEARPROC & AVERPROC & PROCOVER \\
\hline GENDER & -.085 & -.092 & -.029 & -.202 & .058 & -.088 \\
AGE & .029 & -.021 & .158 & -.148 & -.015 & .066 \\
VERBAL SAT & $.296 *$ & .179 & .014 & -.178 & $.329 *$ & .214 \\
MATH SAT & $.288^{*}$ & .231 & .101 & -.168 & $.281 *$ & $.266 *$ \\
SATOVER & $.343 * *$ & .242 & .070 & -.203 & $.356 *$ & $.283 *$ \\
GPA & .088 & .064 & .043 & .027 & .036 & .083 \\
WRITPROC & 1.000 & $.613 * *$ & $.360 * *$ & .172 & $.510^{* *}$ & $.850 *$ \\
STUDPROC & $.613 * *$ & 1.000 & $.325 *$ & .239 & $.395 * *$ & $.824 *$ \\
READPROC & $.360 * *$ & $.325 *$ & 1.000 & .110 & .125 & $.691 *$ \\
FEARPROC & .172 & .239 & .110 & 1.000 & .193 & .221 \\
AVERPROC & $.510 * *$ & $.395 *$ & .125 & .193 & 1.000 & $.445 *$ \\
PROCOVER & $.850 * *$ & $.824 * *$ & $.691 * *$ & .221 & $.445 * *$ & 1.000 \\
\hline
\end{tabular}

$$
\begin{aligned}
* \mathrm{P} & <.05 \\
* * \mathrm{P} & <.01
\end{aligned}
$$


Table 4 Percentage Comparison of Solomon \& Rothblum's

"high" procrastinators, with PASS program students

\begin{tabular}{|l|cccc|}
\hline Proc Items & S\&R(\%) & PASS(\%) & Z Level & Signif \\
\hline WritProc\#1 & 46 & 53 & 0.93 & NS \\
WritProc\#2 & 24 & 32 & 1.26 & NS \\
Studproc\#1 & 28 & 44 & 2.54 & $\star$ \\
StudProc\#2 & 21 & 49 & 5.03 & $*$ \\
ReadProc\#1 & 30 & 40 & 1.50 & NS \\
ReadProc\#2 & 24 & 37 & 2.14 & $*$ \\
\hline
\end{tabular}

$\star P<.05$

$\star \star P<.01$ 
Table 5 part 1 Fear of Failure and Task Aversion

Descriptives

\begin{tabular}{|l|cccc|}
\hline & Gender & Number & Mean & Standard Deviation \\
\hline FearProc & Female & 20 & 10.45 & 4.57 \\
& Male & 37 & 8.90 & 3.11 \\
& Total & 57 & 9.44 & 3.72 \\
& & & & \\
AverProc & Female & 20 & 13.90 & 5.00 \\
& Male & 37 & 14.49 & 4.90 \\
& Total & 57 & 14.30 & 4.90 \\
\hline
\end{tabular}

Table 5 part 2 Ranges of Scores on reasons underlying procrastination

\begin{tabular}{|c|cc|}
\hline & Solomon \& Rothblum & PASS Program Students \\
\hline Fear-of-Failure & $6.3-14.1$ & $5.3-14.0$ \\
Task-Aversion & $19.4-47.0$ & $14.0-49.1$ \\
\hline
\end{tabular}


Appendix B

Consent Form for Release of Information

University of Rhode Island

Department of Human Development \& Family studies

Transition Center

(401) $874-2150$

You are being asked to take part in a study that examines academic procrastination in college students. This study will examine the relationship between student study habits and other student variables. In addition to surveys you completed when you began the PAss program, we are requesting your permission to access the following information from your University College academic record: SAT scores, and G.P.A.

You were selected as a possible participant in this study because of your involvement with the PASS program. Your participation in this study will allow the researcher and University College to learn more about student's needs as they relate to study skills. You must be at least 18 years old to participate in this research project.

There are no risks associated with this project. Your part in this study is confidential. None of the 
information used in the final project will identify you by name.

The decision to take part in this study is up to you. You do not have to participate. If you decide to take part in the study, you may quit at any time. Whatever you decide will in no way affect your standing at URI. If you wish to quit, you may simply inform Janee McFadden at (401) $792-8920$

If you have any questions, please ask us. If you have any additional questions later, you may contact the researcher, Janee McFadden at any point in the future at 792-8920. You may also contact Dr. Jerry Schaffran at 8742270, with additional questions. You may also contact the office of the Vice Provost for Graduate Studies, Research and Outreach, 70 Lower College Road, Suite 2, University of Rhode Island, Kingston, Rhode Island, telephone (401) 8742635 .

You have read the Consent form. Your questions have been answered. Your signature on this form means that you understand the information and you agree to participate in this study.

Please keep the second copy of this consent form for future reference. 
Student signature

Printed Name

Date
Witness signature

Printed Name

Date 
Appendix B

\section{PROCRASTINATION ASSESSMENT SCALE - STUDENTS \\ PASS}

\section{AREAS OF PROCRASTINATION}

For each of the following activities, please rate the degree to which you delay or procrastinate. Rate each item on an a to e scale according to how often you wait until the last minute to do the activity. Then, indicate on an a to e scale the degree to which you feel procrastination on that task is a problem. Finally, indicate on an a to e scale the degree to which you would like to decrease your tendency to procrastinate on each task. Mark your answers on your answer sheet.

I. WRITING A TERM PAPER

1. To what degree do you procrastinate on this task?

Never Almost Never Sometimes Nearly Always Always Procrastinate

a

$\mathrm{b}$

c Procrastinate

d e

2. To what degree is procrastination on this task a problem for you?

Not at all Almost Never Sometimes Nearly Always Always a problem

a

b

c

d a problem

e

3. To what extent do you want to decrease your tendency to procrastinate on this task?

Do not want to decrease

a

b

c

d

\section{STUDYING FOR EXAMS}

4. To what degree do you procrastinate on this task?

Never Almost Never Sometimes Nearly Always Always Procrastinate a

b

c

d Procrastinate

e

5. To what degree is procrastination on this task a problem for you? Not at all Almost Never Sometimes Nearly Always Always a problem a b c d a problem

6. To what extent do you want to decrease your tendency to procrastinate on this task? 
Do not want to decrease a
Somewhat

b

c

d

Definitely

want to decrease

\section{KEEPING UP WITH WEEKLY READING ASSIGNMENTS}

7. To what degree do you procrastinate on this task?

Never Almost Never Sometimes Nearly Always Always Procrastinate

a

b

c Procrastinate

8. To what degree is procrastination on this task a problem for you?

Not at all

a
Almost Never

b
Sometimes

c
Always

a problem

$\mathrm{d}$

e

9. To what extent do you want to decrease your tendency to procrastinate on this task?

Do not want
to decrease

a
Somewhat

c
Definitely

want to decrease

d

e

\section{REASONS FOR PROCRASTINATION}

Think of the last time the following situation occurred. It's near the end of the semester. The term paper you were assigned at the beginning of the semester is due very soon. You have not begun work on this paper. There are reasons why you have been procrastinating on this task.

Rate each of the following reasons on a 5-point scale according to how much it reflects why you procrastinated at the time. Mark your answers on your answer sheet.

Use the scale:

Not at all reflects

why I procrastinated

a
Somewhat

Reflects

b

c

d

Definitely reflects

why I procrastinated

e

10. You were concerned the professor wouldn't like your work.

11. You had a hard time knowing what to include and what not to include in your paper.

12. You waited until a classmate did his or hers, so that he/she could give you some 
advice.

13. You had too many other things to do.

13. There's some information you needed to ask the professor, but you felt uncomfortable approaching him/her.

15. You were worried you would get a bad grade.

16. You resented having to do things assigned by others.

17. You didn't think you knew enough to write the paper.

18. You really disliked writing term papers.

19. You felt overwhelmed by the task.

20. You had difficulty requesting information from other people.

21. You looked forward to the excitement of doing this task at the last minute.

22. You couldn't choose among all the topics.

23. You were concerned that if you did well, your classmates would resent you.

24. You didn't trust yourself to do a good job.

25. You didn't have enough energy to begin the task.

26. You felt it just takes too long to write a term paper.

27. You liked the challenge of waiting until the deadline.

28. You knew that your classmates hadn't started the paper either.

29. You resented people setting deadlines for you.

30. You were concerned you wouldn't meet your own expectations.

31. You were concerned that if you got a good grade, people would have higher expectations of you in the future.

32. You waited to see if the professor would give you some more information about the paper. 
33. You set very high standards for yourself and you worried that you wouldn't be able to meet those standards.

34. You just felt too lazy to write a term paper.

35. Your friends were pressuring you to do other things. 
Appendix B

Answer Sheet

Name:

Last Name (please print)

\section{PASS}

PROCRASTINATION ASSESSMENT SCALE - STUDENTS

\section{AREAS OF PROCRASTINATION}

I. WRITING A TERM PAPER

1. Never Almost Never Sometimes Nearly Always Procrastinate a b c d Always Procrastinate e

2. Not at all a problem

a

3. Do not want to decrease

a
Almost Never Sometimes Nearly Always

b

c

Somewhat

b

c
Always a problem

e

Definitely want to decrease

e

II. STUDYING FOR EXAMS

4. Never Procrastinate

a

5. Not at all a problem

a

6. Do not want to decrease

a
Almost Never

b
Sometimes

c
Nearly Always

d
Always

Procrastinate

e
Nearly Always

d

Somewhat

b

c d
Always a problem

e

Definitely want to decrease

e

III. KEEPING UP WITH WEEKLY READING ASSIGNMENTS

7. Never Procrastinate

a
Almost Never Sometimes

b
Nearly Always

d Always
Procrastinate Always
Procrastinate e 
8. Not at all a

9. Do not want to decrease a
Almost Never Sometimes

b

c

Somewhat

b
Nearly Always

d

Always

a problem

e

Definitely want to decrease

d

e

REASONS FOR PROCRASTINATION

Use the following scale for answers 10-35:

Not at all reflects

why I procrastinated

a
Somewhat

Reflects

c
Definitely reflects why I procrastinated
e

23.

24.

25.

26.

27.

28

29.

30.

31.

32.

33.

34.

35. 


\section{Bibliography}

Bandura, A. (1977). Self-efficacy: Toward a unifying theory of behavioral change. Psychological Review, 84, $191-215$

Beswick, G., Rothblum, E. D., \& Mann, L. (1988). The psychological antecedents of student procrastination. Australian Psychologist, 23 (2), 207-217.

Betz, N.E., \& Hackett, G. (1981). The relationship of career-related self-efficacy expectations to perceived career options in college women and men. Journal of Counseling Psychology, 28, 399-410.

Burka, J. B., \& Yuen, I. M. (1983). Procrastination, why you do it, what to do about it. Reading, MA: Perseus Books.

Effert, B. R., \& Ferrari, J. R. (1989). Decisional procrastination: Examining personality correlates. Journal of Social Behavior \& Personality, 4, 151-156.

Ellis, A., \& Knaus, W. J. (1977). Overcoming procrastination. New York, NY: Penguin Books.

Ferrari, J. (1992). Psychometric validation of two procrastination inventories for adults: Arousal and avoidance measures. Journal of Psychopathology and Behavioral Assessment, 14 (2), 97-109. 
Ferrari, J., Johnson, J., McGown, W. (1995).

Procrastination and task avoidance: Theory, research, \&

treatment. New York, NY: Plenum Press.

Green, L. (1982). Minority students' self-control of procrastination. Journal of Counseling Psychology, 29

(6), 636-644 .

Hong, E. (1998). Differential stability of state and trait self-regulation in academic performance. Journal of Educational Research, 91 (3), 148-157.

Janis, I. L., \& Mann, L. (1977) . Decision-making: A psychological analysis of conflict, choice, and commitment. New York: Free Press. Knaus, w. (1979). Do it now: How to stop procrastinating. New York, NY: Prentice-Hall.

Knaus, w. (1998). Do it now: How to stop procrastinating. (Revised edition). New York, NY: John Wiley \& Sons.

Lay, C. H. (1986). At last, my research article on procrastination. Journal of Research in personality, 20, $474-495$. 
Lent, R., Brown, S., \& Larkin K. (1984). Relation of self-efficacy expectations to academic achievement and persistence. Journal of Counseling Psychology, 31 (3) 356362 .

Maslow, A. (1999). Toward a psychology of being. $3^{\text {rd }}$ edition. New York, NY: John Wiley \& Sons.

MCGown, W. G., \& Johnson, J.L. (1989). Non student validation of an adult inventory of procrastination. Paper presented at the American Psychological Association, New Orleans, LA.

MCCown, W., \& Roberts, R. (1994). A study of academic and work related dysfunctioning relevant to the college version of an indirect measure of impulsive behavior. Integra Technical Paper, 94-28, Radnor, PA: Integra, Inc. Prochaska, J., O., Norcross, J., C., \& DiClemente, C., C. (1994). Changing for good. New York, NY: W. Morrow Publishers.

Roberts, M.S. (1995). Living without procrastination: How to stop postponing your life. Oakland, CA: New Harbinger Publications.

Rothblum, E. D., Solomon L.J., \& Murakami, J. (1986). Affective, cognitive, and behavioral differences between high and low procrastinators. Journal of Counseling Psychology, 33 (4), 387-394. 
Sapadin, L., \& Maguire, J. (1996). It's about time: the six styles of procrastination and how to overcome them. New York, NY: Penguin Books.

Semb, G., \& Glick, M. (1979). Student withdrawals and delayed work patterns in self-paced psychology courses. Teaching of Psychology, 6, 23-25.

Silver, M. (1974). Procrastination. Centerpoint, 1, $49-54$.

Solomon, L.J., \& Rothblum, E.D. (1984). Academic procrastination: Frequency and cognitive-behavioral correlates. Journal of Counseling Psychology, 31 (4), 503509 .

Tuckman, B. (1989). Thinking out loud: Procrastination busting. Educational Technology, 29, 48-49.

Tuckman, B. (1998). Using tests as an incentive to motivate procrastinators to study. Journal of Experimental Education, 66 (2), 141-147.

Van de Kolk. (1987). Psychological trauma-Washington DC: American Psychiatric Association Press.

Weiner, B. (1986). An attributional theory of motivation and emotion. New York, NY: Springer-Verlag. 